\title{
Psicoanálisis frente al algoritmo
}

\author{
Psychoanalysis v. Algorithm
}

Rebeca García Nieto

Escritora. Psicóloga clínica.

Correspondencia: rebecagarcianieto@gmail.com

Gustavo DESSAL (2019), Inconsciente 3.0. Lo que hacemos con las tecnologías y lo que las tecnologías hacen con nosotros. Barcelona, Xoroi Edicions. ISBN: 978-84-121166-4-9, 256 páginas. Prólogo de Javier Peteiro Cartelle. Epílogo de Juan de la Peña.

L psiconalista Gustavo Dessal ha estado siempre muy atento a la cuestión
social; no en vano, hace unos años publicó un libro junto a Zygmunt Bauman. El título del libro - El retorno del péndulo (1) - aludía a una conferencia del conocido sociólogo sobre libertad y seguridad. Para Bauman, ambas formarían una especie de matrimonio mal avenido: aunque están siempre en permanente conflicto, no pueden sobrevivir la una sin la otra. Su convivencia se regiría por una especie de movimiento pendular. Si en la época de Freud las personas buscaban mayor libertad, ahora, en el mundo post 11-S, nos habríamos escorado hacia el otro polo, pues hemos tenido que ceder parte de nuestra libertad para obtener una mayor seguridad.

Este debate, que cobra un nuevo sentido con las nuevas tecnologías, late de fondo en este libro del argentino. Solemos poner el grito en el cielo cuando nos enteramos de que algunos gobiernos interceptan comunicaciones en nombre de la seguridad del Estado, pues consideramos, y con razón, que se podría estar vulnerando nuestro derecho a la privacidad. Sin embargo, a menudo olvidamos que, a cambio de poder utilizar determinadas aplicaciones de móvil o acceder a distintas redes sociales, estamos cediendo nuestros datos a grandes corporaciones. En este libro, muy bien documentado, Dessal reflexiona sobre la actual "fetichización de la tecnología” y nos 
recuerda que detrás de muchas de las aplicaciones y dispositivos que manejamos hay importantes grupos de poder: "El neoliberalismo", escribe Dessal, "a fin de realizar sus designios, manipula los eternos sueños humanos induciendo en ellos el espejismo del progreso". No obstante, el psicoanalista tiene el acierto de no demonizar las nuevas tecnologías y no olvida cómo han contribuido a mejorar nuestras vidas (cita, por ejemplo, al robot Da Vinci, que "ha abierto un extenso campo de posibilidades a la cirugía”), ofreciendo en todo momento una visión equilibrada de la cuestión.

$\mathrm{Al}$ margen de este aspecto más ideológico, Dessal ahonda en los cambios que el desarrollo tecnológico está produciendo en nuestra subjetividad y en las razones por las que un buen número de personas se han "enganchado" a las nuevas tecnologías. La sociedad de consumo en que vivimos ha sabido sacar partido de la naturaleza de nuestro deseo, moldeando este a su antojo. El principal logro del capitalismo es habernos hecho creer que nuestros deseos son nuestros, cuando en verdad han sido otros los que nos han metido esos objetos de deseo por los ojos. Pero, además, los creadores de aplicaciones, los artífices de las redes sociales, etc. han sabido aprovechar algunos aspectos característicos de la condición humana. Un elemento que ha contribuido a su éxito es el hecho de que ofrecen un contenido supuestamente "personalizado" (de hecho, esta es una de las excusas que aducen para recabar nuestros datos). Esta "personalización", por supuesto, es ficticia, puesto que se basa en algoritmos establecidos mediante medidas de semejanza con el resto de usuarios. Como señala Dessal, estas empresas se las ingenian para activar "uno de los resortes más poderosos del ser humano: su paradójico deseo de ser único y a la vez normal, es decir, igual que todos los demás". Otro aspecto, no menor, es nuestra necesidad de ficción: "(...) el ser humano no ha podido ni podrá jamás soportar su vida sin el auxilio de un artificio (simbólico, imaginario o real) que lo separe de su mísera existencia, empujada hacia la deriva de la certidumbre". Las redes sociales nos dan la oportunidad de ser otros sin dejar de ser nosotros, nos permiten aparentar una felicidad que nos es inalcanzable. En definitiva, nos permiten llevar una vida "como si”, y es difícil encontrar algo más adictivo que eso.

Uno de los proyectos más curiosos de los que cita Dessal es el Quantified Self-o Yo Cuantificado-. Nuestros datos son sinónimo de dinero, y el hecho de que algunas personas se hayan "enganchado" a los dispositivos de self-tracking-autorrastreo-y no puedan pasar un solo día sin conocer sus pulsaciones, los pasos que dan o las calorías que consumen demuestra hasta qué punto han tenido éxito las corporaciones que hay detrás de estos dispositivos, pues se las han ingeniado para que sean los propios usuarios quienes se los faciliten gustosos. Este tipo de dispositivos de automonitorización han llegado también a la salud mental. De hecho, en esta misma Revista se publicó hace unos años una magnífica revisión crítica sobre esta cuestión (2). Dessal avisa de que "algunos ingenieros están empeñados en arrebatarle el cuerpo humano 
a la medicina”, y, a juzgar por algunos proyectos de investigación que se han iniciado en los últimos años, que pretenden caracterizar el comportamiento humano a través de algoritmos creados mediante la agregación de datos a gran escala, parece que no anda muy desencaminado.

No obstante, cabe preguntarse sobre la precisión de estos algoritmos. El psicoanalista cree que lo más específico de cada hombre, su singularidad, queda fuera del alcance de estas formulaciones ("al menos de momento, no existe un modo de traducir el goce al cálculo"). Es más, defiende que el saber del inconsciente y el de los datos se oponen: "El sujeto es una excepción a los objetos que la ciencia puede abordar, puesto que su lógica no admite una reducción a los algoritmos del universo físico matemático, ni a los datos secuenciales estudiados por la biología”. En contraposición a este ser humano reducido a fórmulas matemáticas parciales, este ser humano "sin inconsciente" (por tanto, no del todo humano), que cree que puede satisfacer todos sus deseos aunque se siente permanentemente insatisfecho, el psicoanálisis se centra en la herida que le es más propia, la de su división, y no se propone "curarle", "sino, por el contrario demostrar su incurabilidad, dándole al analizante la oportunidad de encontrar un síntoma menos idiota con el que afrontar su existencia”.

El psicoanálisis lleva tiempo nadando a contracorriente, pero tal vez ahora lo haga más que nunca. En general, no corren buenos tiempos para todo aquello que no sea rápido, inmediato, superficial. Por eso mismo, libros como este, que te obligan a pararte a pensar en lo que habitualmente hacemos de forma automática, son más necesarios que nunca. Urge pensar en qué estamos haciendo con las tecnologías y, sobre todo, qué están haciendo ellas con nosotros. Sin duda, un libro más que oportuno.

\section{Bibliografía}

(1) Bauman Z, Dessal G. El retorno del péndulo. Madrid: Fondo de Cultura Económica, 2014.

(2) López-Santín JM, Álvaro Serón P. La salud mental digital. Una aproximación crítica desde la ética. Rev Asoc Esp Neuropsiq. 2018; 38(134): 359-379. 